$1 N-21$

NASA/TM-1998-208654

432192

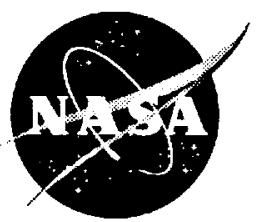

\title{
Evaluation of Several Space Lubricants Using a Vacuum Four-Ball Tribometer
}

William R. Jones, Jr.

Lewis Research Center, Cleveland, Ohio

Agnieszka K. Poslowski

John Carroll University, University Heights, Ohio

Bradley A. Shogrin

Case Western Reserve University, Cleveland, Ohio

Pilar Herrera-Fierro

Ohio Aerospace Institute, Brook Park, Ohio

Mark J. Jansen

AYT Corporation, Brook Park, Ohio 
Since its founding, NASA has been dedicated to the advancement of aeronautics and space science. The NASA Scientific and Technical Information (STI) Program Office plays a key part in helping NASA maintain this important role.

The NASA STI Program Office is operated by Langley Research Center, the Lead Center for NASA's scientific and technical information. The NASA STI Program Office provides access to the NASA STI Database, the largest collection of aeronautical and space science STI in the world. The Program Office is also NASA's institutional mechanism for disseminating the results of its research and development activities. These results are published by NASA in the NASA STI Report Series, which includes the following report types:

- TECHNICAL PUBLICATION. Reports of completed research or a major significant phase of research that present the results of NASA programs and include extensive data or theoretical analysis. Includes compilations of significant scientific and technical data and information deemed to be of continuing reference value. NASA's counterpart of peerreviewed formal professional papers but has less stringent limitations on manuscript length and extent of graphic presentations.

- TECHNICAL MEMORANDUM. Scientific and technical findings that are preliminary or of specialized interest, e.g., quick release reports, working papers, and bibliographies that contain minimal annotation. Does not contain extensive analysis.

- CONTRACTOR REPORT. Scientific and technical findings by NASA-sponsored contractors and grantees.
- CONFERENCE PUBLICATION. Collected papers from scientific and technical conferences, symposia, seminars, or other meetings sponsored or cosponsored by NASA.

- SPECIAL PUBLICATION. Scientific, technical, or historical information from NASA programs, projects, and missions, often concerned with subjects having substantial public interest.

- TECHNICAL TRANSLATION. Englishlanguage translations of foreign scientific and technical material pertinent to NASA's mission.

Specialized services that complement the STI Program Office's diverse offerings include creating custom thesauri, building customized data bases, organizing and publishing research results ... even providing videos.

For more information about the NASA STI Program Office, see the following:

- Access the NASA STI Program Home Page at http://www.sti.nasa.gov

- E-mail your question via the Internet to help@sti.nasa.gov

- Fax your question to the NASA Access Help Desk at (301) 621-0134

- Telephone the NASA Access Help Desk at (301) 621-0390

- Write to: NASA Access Help Desk NASA Center for AeroSpace Information 7121 Standard Drive Hanover, MD 21076 
NASA/TM-1998-208654

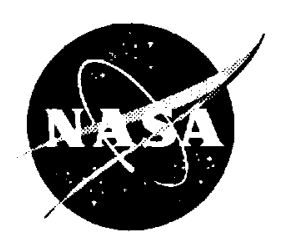

\section{Evaluation of Several Space Lubricants Using a Vacuum Four-Ball Tribometer}

William R. Jones, Jr.

Lewis Research Center, Cleveland, Ohio

Agnieszka K. Poslowski

John Carroll University, University Heights, Ohio

Bradley A. Shogrin

Case Western Reserve University, Cleveland, Ohio

Pilar Herrera-Fierro

Ohio Aerospace Institute, Brook Park, Ohio

Mark J. Jansen

AYT Corporation, Brook Park, Ohio

Prepared for the International Tribology Conference and Exposition sponsored by the American Society of Mechanical Engineers and the Society of Tribologists and Lubrication Engineers

Toronto, Canada, October 25-28, 1998

National Aeronautics and

Space Administration

Lewis Research Center 
Available from

NASA Center for Aerospace Information 7121 Standard Drive Hanover, MD 21076

Price Code: A03
National Technical Information Service 5285 Port Royal Road Springfield, VA 22100 Price Code: $\mathrm{A} 03$ 


\title{
USING A VACUUM FOUR-BALL TRIBOMETER
}

\author{
William R. Jones, Jr. \\ National Aeronautics and Space Administration \\ Lewis Research Center \\ Cleveland, Ohio 441.35 \\ Agnieszka K. Poslowski \\ John Carroll University \\ University Heights, Ohio 44118 \\ Bradley A. Shogrin \\ Case Western Reserve University \\ Cleveland, Ohio 44106 \\ Pilar Herrera-Fierro \\ Ohio Aerospace Institute \\ Brookpark, Ohio 44142 \\ Mark J. Jansen \\ AYT Corp. \\ Brookpark, Ohio 44142
}

\section{SUMMARY}

The friction and wear behavior of seven space lubricants was investigated under boundary lubrication conditions using a vacuum four-ball tribometer. Three of the lubricants were perfluoropolyethers (143AC, S-200, and Z-25). Three were synthetic hydrocarbons (a multiply alkylated cyclopentane, 2001a), and a formulated version with an antiwear and an antioxidant additive $(2001)$. The third hydrocarbon was an unformulated polyalphaolefin (PAO-100). An unformulated silahydrocarbon (SiHC) was also evaluated. Test conditions included: a pressure $<6.7 \times 10^{-4} \mathrm{~Pa}$, a $200 \mathrm{~N}$ load, a sliding velocity of $28.8 \mathrm{~mm} / \mathrm{sec}(100 \mathrm{rpm})$, and room temperature $\left(\sim 23^{\circ} \mathrm{C}\right)$. The wear rate for each lubricant was determined from the slope of wear volume as a function of sliding distance. The lowest wear rate $\left(0.033 \times 10^{-9} \mathrm{~mm}^{3} / \mathrm{mm}\right)$ was obtained with the silahydrocarbon. The formulated synthetic hydrocarbon had a wear rate of $0.037 \times 10^{-9} \mathrm{~mm} / 3 / \mathrm{mm}$, which was a 36 percent reduction compared to the unformulated fluid. The polyalphaolefin had the highest wear rate of the non-PFPE fluids. Of the perfluoropolyethers (PFPEs), wear rates decreased by about 50 percent from Z-25 $\left(1.7 \times 10^{-19} \mathrm{~mm}^{3} / \mathrm{mm}^{2} 10\right.$ S-200 $\left(0.70 \times 10^{-9} \mathrm{~mm}^{3} / \mathrm{mm}\right)$ to $143 \mathrm{AC}\left(0.21 \times 10^{-9} \mathrm{~mm}^{3} / \mathrm{mm}\right)$.

\section{INTRODUCTION}

In the past, space components such as electronics, batteries, and thermal and optical systems were the main causes of spacecraft failure (Ref. 1). However, with the many advances taking place in improving these components, tribology is being exposed as the major roadblock to achieving critical mission requirements such as increased mission life and greater reliability. Spacecraft designers are constantly in need of tribological data (e.g., torque, wear characteristics, lubricant degradation, and outgassing characteristics) for various material/lubricant combinations (Ref. 2).

Liquid lubricants are frequently used in space mechanisms because they are associated with low mechanical noise, no wear in the elastohydrodynamic (EHL) regime, ease of replenishment, ability to remove wear debris, and an insensitivity to environmental factors (Ref. 2). Esters, mineral oils, polyalphaolefins, perfluoropolyethers (PFPE), synthetic multiply-alkylated cyclopentanes (Ref. 3), and silahydrocarbons (Ref. 4) are the different chemical hase stocks with space heritage or are potential candidates for space applications. The class of synthetic hydrocarbon fluids called multiply-alkylated cyclopentanes (MACs) have received increasing attention as possible space lubricants. These lubricants, in which two to five alkyl groups are attached to one cyclopentane ring, are the result of reacting dicyclopentadiene with commercially available alcohols (Ref. 3). They can be synthesized with a wide range of physical properties depending upon the number and 
nature of the alkyl substituent groups (Ref. 3). Hence, the wide availability of a number of commercial alcohols allows for the preparation of alkylcyclopentanes with vast combinations of properties. Also, since MACs are hydrocarbons, many of the commercially available antiwear, extreme pressure, and antioxidant additives are soluble in them and can be used to further enhance their performance. However, only one MAC is commercially available which is a mixture of the di- and tri- substituted (2-octyldodecyl) cyclopentane.

Unlike the hydrocarbons, perfluoropolyethers are extensively used neat (pure) as space lubricants because of their insolubility with the above mentioned additives. These fluids have high intrinsic thermal (Ref. 5) and chemical stabilities (Ref. 6) and are particularly effective in the elastohydrodynamic regime (Ref. 7). However, PFPEs decompose when they are in contact with Lewis acids (refs. 8 10 10), various metals and their oxides (refs. 11 to 13), and under certain tribological conditions (refs. 14 to 16). Also, when used as boundary lubricants, PFPEs exhibit more variable and less predictable behavior than conventional lubricants, such as hydrocarbons, esters, and polyalphaolefins (Ref. 14).

A new class of synthetic lubricants, known as the silahydrocarbons, are being developed for use in space (refs. 4,17 and 18). These materials contain only silicon, carbon, and hydrogen. They are unimolecular compounds with extremely low volatility. By changing the length of the carbon chain, a series of compounds with a range of viscosities can be produced. In addition, these compounds will readily accept conventional lubricant additives developed for hydrocarbons.

Therefore, the objective of this work was to compare the steady state wear rates and coefficients of friction of several PFPEs, hydrocarbons, and a silahydrocarbon. A vacuum four-ball apparatus was cmployed to evaluate the lubricants. First, the results of the PFPEs were evaluated against each other and then compared to the hydrocarbons and silahydrocarbon. The effects of the additives in the hydrocarbon on the reduction of wear was also shown. Surface analysis (FTIR and Raman spectroscopies) was performed on some post-test wear specimens.

\section{EXPERIMENTAL}

\section{Lubricants}

Friction and wear characteristics of seven lubricants and lubricant formulations were evaluated in vacuum. The structures of these lubricants appear in Table I, and some of their physical properties (from manufacturer's data) appear in Table II. Of these, three were commercially available PFPEs: S-200, Z-25, and 143AC. These products are formed by polymerization of perfluorinated monomers. $143 \mathrm{AC}$ is synthesized by CsF catalyzed polymerization of hexafluoropropenc oxide, and it is composed of a series of branched polymers (Ref. 19). The linear polymer, Z-25, is produced by UV catalyzed photo-oxidation of tetrafluoroethylene (Ref. 20). The third polymer, S-200, is synthesized by polymerization of tetrafluorooxetane followed by direct fluorination (Ref. 21). The synthetic hydrocarbons tested included an unformulated MAC (2001a) and an additive version (2001). The MAC base fluid is a mixture of di- and tri(2-octyldodecyl)cyclopentane, and the formulated version contains the base fluid, a mixture of phosphate esters (an antiwear additive), and a hindered phenol (an antioxidant). The other hydrocarbon is a high molecular weight unformulated polyalphaolefin (PAO-100). The last fluid is an unformulated pentasilahydrocarbon, $\mathrm{Si}\left[\mathrm{C}_{3} \mathrm{H}_{6} \mathrm{Si}\left(\mathrm{C}_{12} \mathrm{H}_{25}\right)_{3}\right]_{4}$.

\section{Tribometer}

A four-hall tribometer (Fig. 1), operating in the boundary lubrication mode, was used to measure steady state wear rates and friction coefficients for each lubricant. Specimen configuration (Fig. 2) is the same as the ordinary four-ball apparatus, except $9.5 \mathrm{~mm}$ (3/8 in.) diameter $440 \mathrm{C}$ stainless stecl precision bearing balls (grade 10) are used. A complete description of this device appears in reference 22.

\section{Test Procedure}

Cleaning and Preparation.--The test balls and the lubricant cup were ultrasonically cleaned sequentially in baths of hexane, acetone, and ethanol for $10 \mathrm{~min}$. The balls and lubricant cup were dried with nitrogen after the final ultrasonic cleaning. Just prior to rig assembly, a final cleaning of the balls occurred with a 15 min UV/ozone treatment, rotating the balls every $5 \mathrm{~min}$. Within $5 \mathrm{~min}$ of this treatment, one ball was placed into the nitrogen-purged tribometer and used as the rotating ball. The other three balls were secured into the lubricant cup and covered with the test fluid $(-5 \mathrm{ml})$. The cup was then placed into a hell jar for 30 min which was 
evacuated with a mechanical pump to remove dissolved gases. The cup was placed on the stage inside the tribometer and the chamber was evacuated.

Testing.- The experiment was started after reaching a chamber pressure of $<6.7 \times 10^{-4} \mathrm{~Pa}$. The stage was pneumatically loaded against the upper ball and rotation initiated. All tests were performed at room temperature, a load of $200 \mathrm{~N}$ (an initial Hertzian stress of $3.5 \mathrm{GPa}$ ), and a sliding speed of $28.8 \mathrm{~mm} / \mathrm{sec}$ (rotating ball speed of $100 \mathrm{rpm}$ ). The frictional torque was monitored and recorded throughout the experiment. A Hall-effect sensor provided an indirect measurement of torque by determining the relative angular displacement of the lubricant cup which was attached to a flex pivot. The system is calibrated statically by using a dead weight loading fixture. Between 4 and 6 tests were performed on each lubricant.

Wear was determined by measuring the wear scar diameters on the three stationary balls using an optical microscope and calculating an average. The sample stage on the optical microscope was designed so that the wear scars could be measured without removing the balls from the cup. The experiment was then continued using the same set of balls. A complete test run was four hours in length with interruptions every hour for wear scar measurements. At test conclusion, a wear rate $\left(\mathrm{mm}^{3} / \mathrm{mm}\right)$ was calculated from the slope of the straight line which was obtained from a plot of wear volume as a function of sliding distance. Correlation coefficients were typically $>0.97$. An example of data from a typical test (PFPE Z-25) is shown in figure 3. Each of the four data points represents the average of the three balls for one wear scar measurement, which typically vary \pm 5 percent.

\section{Surface Analysis}

One stationary ball from one test using Z-25, 143AC, S-200 (rinsed in trichlorotrifluoroethane) and MAC 2001 a (rinsed in hexane) was analyzed with a Fourier transform infrared microscope ( $\mu$-FTIR) in the reflectance mode using a Grazing Angle Objective $(\mathrm{GAO})$ and a $100 \mu \mathrm{m}$ diameter spot size. The spectral resolution and acquisition time were $8 \mathrm{~cm}^{-1}$ and $400 \mathrm{sec}$, respectively. A gold coated glass slide was used to acquire a background spectrum. Also, Raman spectra of the steel surfaces were taken on the same halls. Balls from tests with MAC 2001, PAO-100 and the silahydrocarbon were examined visually, but not analyzed.

Raman analysis was performed using a $15 \mathrm{~mW}$ Ar laser $(514.5 \mathrm{~nm}$ wavelength), with an analyzing spot diameter of $2 \mu \mathrm{m}$, and a $50 \mathrm{X}$ objective. The acquisition time was $50 \mathrm{sec}$ and the spectral range was 400 to $3200 \mathrm{~cm}^{-1}$. The instrument was aligned to both the type $2 \mathrm{~A}$ diamond line at $1331.2 \mathrm{~cm}{ }^{1}$ and $\mathrm{Si}(100) \mathrm{at}$ $520.8 \mathrm{~cm}^{-1}$. Care was taken when exposing the films to the laser beam since damage can occur that mimics degradation produced by a tribological process. This was done by limiting the acquisition time and checking standards periodically to assure that no artifacts were being introduced.

\section{RESULTS}

\section{Wear}

Wear results, including standard deviations, appear in Table III for all lubricants. The number of tests performed with each lubricant appears within the parentheses in the respective lubricant column. The PFPEs possessed higher wear rates than the hydrocarbons or silahydrocarbon. The PFPE wear rates decreased by approximately 50 percent from Z-25 $\left(1.7 \times 10^{-9} \mathrm{~mm}^{3} / \mathrm{mm}\right)$ to $\mathrm{S}-200\left(0.70 \times 10^{-9} \mathrm{~mm} / \mathrm{mm}\right)$ to $143 \mathrm{AC}$ $\left(0.21 \times 10^{-1} \mathrm{~mm}^{3} / \mathrm{mm}\right)$. MAC 2001 (formulated) had a 36 percent reduction in wear rate as compared to the unformulated fluid (200la). However, both had a lower wear rate than any of the PFPEs. The unformulated polyalphaolefin (PAO-100) yiclded a higher wear rate $\left(0.13 \times 10^{9} \mathrm{~mm} / \mathrm{mm}\right)$ than the MACs. The lowest wear rate was obtained with the unformulated silahydrocarbon $\left(0.033 \times 10^{-9} \mathrm{~mm}^{3} / \mathrm{mm}\right)$. Wear results are shown graphically in Figure 4, where the error bars represent one standard deviation.

\section{Friction}

The friction coefficient results are also shown in Table III. The mean friction coefficient values are indicated, while the ranges attained throughout the runs for each lubricant are within the parentheses. The mean friction results are shown graphically in Fgure 5, where the error bars represent the minimum and maximum friction coefficient observed for each lubricant. All lubricants had a mean friction coefficient between 0.08 to 0.12 . 


\section{Surface Analysis}

The wear experiments were done in two stages. Therefore, all lubricant post-test specimens were not analyzed. Areas on and off of the wear scars were inspected for tribologically induced products left on the metal surfaces. Organic and inorganic compounds were identified on the surface of the post-wear balls using the PFPE lubricants, but only organic species were found for the synthetic hydrocarbon (MAC 2001a). Brown deposits were observed on the off-scar and on-scar regions of the examined then 143AC. On the other hand, the $\mu$-FTIR spectra for the MAC identified only one weak signal between 2850 balls. Z-25 and S-200 showed the most debris in the off scar regions, with $143 \mathrm{AC}$ forming considerably less, and the 200la producing fairly clean surfaces. The on-scar regions contained both clean metal and areas of residue for all lubricants.

FTIR.-The M-FTIR on-scar spectra revealed the presence of hydroxide $\left(300010.3600 \mathrm{~cm}^{-1}\right)$, organic fluorocarbons (1000 to $\left.1350 \mathrm{~cm}^{-1}\right)$, and carboxylate $\left(\sim 1650 \mathrm{~cm}^{-1}\right)$ for the PFPE lubricated balls and only $\mathrm{C}-\mathrm{H}$ signals (2850 to $3000 \mathrm{~cm}^{-1}$ ) for the hydrocarbon (2001a). Of the PFPEs, the Z-25 lubricated steel registered the strongest signals for hydroxide, organic fluorocarbons, and a carboxylate at the off-scar areas followed by $\mathrm{S}-200$ and 143AC. A representative spectrum for Z-25 is shown in Figure 6. This spectrum is similar to the spectrum obtained for 143AC in ball-on-disk experiments (Ref. 23). On-scar areas yielded the same species for the three PFPE lubricants but in reduced amounts.

Qualitatively, the $\mu$-FTIR analysis showed that the quantity of reaction products on the steel surfaces using the PFPE lubricants was greatest for Z-25, followed by S-200, and then 143AC. On the other hand, the $\mu$-FTIR spectra for the MAC identified only one weak signal between 2850 to $3000 \mathrm{~cm}^{-1}$ for $\mathrm{C}-\mathrm{H}$. This suggests that the synthetic hydrocarbon $(2001 \mathrm{a})$ produces negligible residue under these tribological conditions.

Raman.-The Raman spectral analysis identified a carbonaceous cross-linked residue with graphitic characteristics as the major deposit on and off of the scarred areas for all of the lubricants analyzed (the formulated MAC and the silahydrocarbon specimens were not analyzed since they were included from an earlier study). Also, 143AC showed a distinct signal for an inorganic oxide residue, with the other lubricants revealing much smaller quantities (Fig. 7). This assignment was verified with iron oxide standards. Overall, during the tribological process, the lubricants undergo decomposition which eventually degrades their long organic chains into a final carbonaceous form. This has been observed in other experiments performed in a nitrogen atmosphere using a ball-on-disk apparatus and a branched PFPE lubricant (143AC) (Ref. 23). The degradation of fluorinated polymers in lubricated conlacts in vacuum has been well documented. In a series of papers Sugimoto and Miyake (refs. 24 to 26) studied the progressive degradation of sputtered films of polychlorotrifluoroethylene and polytetrafluorocthylene sliding against $440 \mathrm{C}$ steel. Using a variety of surface analytical techniques, they clearly demonstrated the progressive conversion of these materials into a fluorine deficient material and finally, into an amorphous carbon network.

\section{DISCUSSION}

PFPE base lubricants normally operate in the corrosive wear regime under boundary lubrication conditions (Ref. 7). For a detailed discussion of the boundary lubrication regime as well as corrosive wear effects, references 27 and 28 are suggested. In boundary contacts, PFPE fluids react with the bearing surfaces producing a series of corrosive products. These products then react with existing surface oxides resulting in the production of metal fluorides (refs. 1.3 and 15). Fluorides are effective solid lubricants which provide protection for the contact surfaces, thus, reducing wear and friction, compared to the unlubricated case. Nonetheless, the fluorides also attack and decompose the PFPEs which causes the production of even more reactive species. The surface fluorides are constantly removed from the sliding contact region which is the reason for a high substrate wear rate (i.e. corrosive wear) (refs. 15 and 29). Overall, the very reaction that enables unformulated PFPEs to protect surfaces, eventually leads to their destruction. Normally, the amount of degradation products around the wear scar correlates with the wear rate (Ref. 23). This is also reflected in the strength of the features in the infrared spectra (Ref. 29). In the present study, the amount of degradation products shown by FTIR also correlated with wear rale for the three PFPEs.

Mori et al., (Ref. 30) and Masuko et al., (Ref. 31) have reported friction and wear properties on essentially the same PFPE lubricants in vacuum. Mori el al., reported the same order for traction coefficients as shown in the present work: $143 \mathrm{AC}>\mathrm{S}-200>\mathrm{Z}-25$. Masuko et al, reported wear rates on the same fluids to be: Z-25 > $\mathrm{S}-200>143 \mathrm{AC}$. This also agrees with the results presented herein. Both authors concluded that the high wear rate and low friction coefficient observed with the Z-25 type of PFPE is due to its high reactivity with steel surfaces thus generating metal fluorides which promoted chemical (i.e., corrosive wear).

Mori et al., (Ref. 15) also observed the formation of high molecular weight polymers which were polymerized or cross-linked during the sliding experiments. More recently, Pepper and Kingsbury (Ref. 32) observed 
friction polymer formation in ball-on-plate tests in vacuum with the Z-25 lubricant. Gas evolution accompanied the formation of solid-like materials in the tribological contacts in both studies.

In contrast to the PFPEs, unformulated hydrocarbon lubricants are less reactive and operate in the adhesive wear regime under boundary conditions (Ref. 28). Some protective friction polymer (Ref. 33) is formed, but to enhance performance, hydrocarbons are formulated with reactive antiwear or extreme pressure additives. In this case, the MAC was tested with and without the antiwear and antioxidant compounds. Results showed a 36 percent decrease in wear rate for the formulated MAC (2001), as compared to the unformulated version (200la). However, an even lower wear rate was observed with the unformulated silahydrocarbon. The mechanism of wear reduction is not clear with this particular lubricant.

Through surface analysis, organic and inorganic compounds have been identified on the surface of the post-wear balls using the PFPE lubricants and an organic compound using the MAC. The post-wear PFPE lubricated balls contained hydroxide, inorganic oxide, organic fluorocarbons and carbonyl compounds, and the MAC lubricated balls contained alkanes. For both the MAC and the PFPEs, graphitic carbon was identified on the surface, oxide was also identified for the PFPE lubricated balls. The inorganic component of the PFPE lubricated surface layer consisted of the original oxide and hydroxide. The organic components (carbonyl groups, organic fluorocarbons, and graphitic carbon) can be attributed to the nondegraded lubricant and degradation products. The MAC surface residue only consisted of alkanes and graphitic carbon, resulting in a fairly clean surface.

\section{SUMMARY OF RESULTS}

1. The lowest wear rate was obtained with an unformulated silahydrocarbon $\left(0.033 \times 10^{-9} \mathrm{~mm} / \mathrm{mm}\right)$.

2. The wear rates of the perfluoropolyethers were higher than the hydrocarbons, decreasing by approximately 50 percent from Z-25 $\left(1.7 \times 10^{-9} \mathrm{~mm}^{3} / \mathrm{mm}\right)$ to $S-200\left(0.70 \times 10^{-9} \mathrm{~mm}^{3} / \mathrm{mm}\right)$ to $143 \mathrm{AC}$ $\left(0.21 \times 10^{-9} \mathrm{~mm}^{3} / \mathrm{mm}\right)$.

3. The formulated MAC $(2001)\left(0.037 \times 10^{-4} \mathrm{~mm}^{3} / \mathrm{mm}\right)$ had a 36 percent wear rate reduction as compared to the unformulated version $(200 \mathrm{la})\left(0.058 \times 10^{-9} \mathrm{~mm} / \mathrm{mm}\right)$. A higher wear rate was obtained with the other hydrocarbon, an unformulated polyalphaolefin (PAO-100) $\left(0.13 \times 10^{-9} \mathrm{~mm} / \mathrm{mm}\right)$.

4. Infrared spectroscopy and Raman spectroscopy revealed degradation products on the PFPE lubricated, and to a lesser extent, on the MAC 2001 a lubricated surfaces. The amount of degradation products observed in the infrared correlated with the amount of wear.

5. As a result of the tribological process to which these lubricants are subjected, a common degradation product for all lubricants (except the silahydrocarbon) is a highly cross-linked carbonaceous product with graphitic characteristics.

\section{REFERENCES}

1. Fleischauer, P.D. and Hiton, M.R.: "Assessment of the Tribological Requirements of Advanced Spacecraft Mechanisms," Aerospace Corporation, El Segundo, CA, Report No. TOF-0090 (5064)-1, (1991).

2. Jones, W.R., Jr., Pepper, S.V., Herrera-Fierro, P., Feuchter, D., Toddy, T.J., Jayne, D.T., Wheeler, D.R., Abel, P.B., Kingsbury, E., Morales, W., Jansen, R., Ebihara, B., Helmick, L.S., Masuko, M.: "The Preliminary Evaluation of Liquid Lubricants for Space Applications by Vacuum Tribometry," 28th Aerospace Mech. Symp., NASA Lewis Research Center, Cleveland, OH (1994).

3. Vernier, C.G.: "Multiply-Alkylated Cyclopentanes (MACS): A New Class of Synthesized Hydrocarbon Fluids," Lubr. Eng., 47, 7, pp. 586-591, (1991).

4. Tamborski, C., Chen, G.J., Anderson, D.R., and Snyder, C.E., Jr.: "Synthesis and Properties of Silahydrocarbons, A Class of Thermally Stable, Wide-Liquid-Range Fluids," Ind. Eng. Chem. Prod. Res. Dev., 22, p. $172,(1983)$.

5. Helmick, L.S. and Jones, W.R., Jr.: "Determination of the Thermal Stability of Perfluoropolyalkyl Ethers by Tensimetry," Lubr. Eng., 50, 6, p. 449 (1994).

6. Del Pesco, T.W.: "Perfluoroalkylpolyethers," Chapter 6 in Synthetic Lubricants and High-Performance Functional Fluids, ed. R.L. Shubkin, Marcel Dekker, New York, pp. 145-172 (1993).

7. Jones, W.R., Jr.: "The Properties of Perfluoropolyethers Used for Space Applications," Trib. Trans., 38, 3, pp. 557-564 (1995).

8. Zehe, M.J., and Faut, O.D.: "Acidic Attack of Perfluorinated Alkyl Ether Lubricant Molecules by Metal Oxide Surfaces," Trib. Trans., 33, 4, pp. 634-640, (1990). 
9. Carré, D.J.: "The Reaction of Perfluoropolyalkylether Oil with $\mathrm{FeF}_{3}, \mathrm{AlF}_{3}$, and $\mathrm{AlCl}_{3}$ at Elevated Temperatures," ASLE Trans., 28, 1, pp. 40-46, (1985).

10. Kasai, P.H.: "Perfluoropolyethers: Intramolecular Disproportionation," Macromolecules, 25, pp. 6791-6799, (1992).

11. Jones, W.R., Jr., Paciorek, K.J.L., Harris, D.H., Smythe, M.E., Nakahara, J.H., and Kratzer, R.H.: "The Effects of Metals and Inhibitors on Thermal Oxidative Degradation Reactions of Unbranched Perfluopolyalkyl Ethers," Ind. Eng. Chem. Prod. Res. Dev., 24, pp. 417-470, (1985).

12. Herrera-Fierro, P., Pepper, S.V., and Jones, W.R., Jr.: "X-Ray Photoelectron Spectroscopy Study of the Stability of Fomblin Z-25 on the Native Oxide of Aluminum," J. Vac. Sci. Tech., A 10, pp. 2746-275I, (1992).

13. Herrera-Fierro, P., Jones, W.R., Jr., and Pepper, S.V.: "Interfacial Chemistry of a Perfluoropolyether Lubricant Studied by X-ray Photoelectron Spectroscopy and Temperature Desorption Spectroscopy," J. Vac. Sci. Tech., Al1, pp. 354-367, (1993).

14. Conley, P.L., and Bohner, J.J.: "Experience with Synthetic Fluorinated Fluid Lubricants," 24th Acrospace Mechanisms Symposium, NASA CP-3062, pp. 213-230, (1990).

15. Mori, S. and Morales, W.: "Tribological Reactions of Perfluoroalkyl Polyether Oils with Stainless Steel Under Ultrahigh Vacuum Conditions at Room Temperature," Wear, 132, pp. 11-121, (1989).

16. Carré, D.J.: "The Performance of Perfluoropolyalkyl Ethers Under Boundary Condition," Trib. Trans., 31,4 pp. $437-441,(1988)$.

17. Paciorek, K.J.L., Shih, J.G., Kratzer, R.H., Randolph, B.B., and Snyder, C.E., Jr.: "Polysilahydrocarbon Synthetic Fluids. 1. Synthesis and Characterization of Trisilahydrocarbons," I\&EC Research, 29, pp. 1855-1858, (1990).

18. Paciorek, K.J.L., Shih, J.G., Kratzer, R.H., Randolph, B.B., and Snyder, C.E., Jr.: "Polysilahydrocarbon Synthetic Fluids. 2. Synthesis and Characterization of Tetrasilahydrocarbons," I\&EC Research, 30, PP. 2191-2194, (1991).

19. Gumprecht, W.H.: "PR-143--A New Class of High-Temperature Fluids," ASLE Trans., 9, pp. 24-30, (1966).

20. Sianesi, D., Pasetti, A., Fontanelli, R., Bernardi, G.C. and Caporricio, G.: "Perfluoropolyethers by Photooxidation of Fluoroolefins," Chim Ind. (Milan) 55, pp. 208-221, (1973).

21. Ohsaka, Y.: "Recent Advances in Synthetic Lubricating Oils. (8). Perfluorinated Polyethers," Petrotech (Tokyo), 8, 9, pp. 840-843, (1985).

22. Masuko, M., Jones, W.R., Jr., Jansen, R., Ebibara, B., Pepper, S.V., and Helmick, L.: “A Vacuum FourBall Tribometer to Evaluate Liquid Lubricants for Space Applications," Lub. Eng., 5, 11, pp. 871-875, (1994).

23. Herrera-Fierro, P., Shogrin, B. and Jones, William R., Jr.: "Spectroscopic Analysis of Perfluoropolyether Lubricant Degradation During Boundary Lubrication," NASA TM-107299, Lewis Research Center, Sept. (1996).

24. Sugimoto, I., and Miyake, S.: "Surface Microanalytical Study on the Tribological Interface Between the Sputtered Fluoropolymer Film and a Sliding Ball," J. Appl. Phys., 65, 2, pp. 767-774, (1989).

25. Sugimoto, I., and Miyake, S.: "High Lubrication Performance of Tribologically Oriented Fluoropolymer Molecules Analyzed by Polarized Infrared Microspectroscopy," J. Appl. Phys., 67, 9, pp. 4083-4089, (1990).

26. Sugimoto, I., and Miyake, S.: "Tribological Behavior of C-F Bonds in Plasma-Synthesized Fluoropolymers Analyzed by Polarized Infrared Microspectroscopy," J. Appl. Phys., 70, 5, pp. 2618-2622, (1991).

27. Jones, W.R., Jr.: "Boundary Lubrication-Revisited," NASA TM-82858, Lewis Research Center, Cleveland, $\mathrm{OH}(1982)$.

28. Rowe, C.N.: "Wear-Corrosion and Erosion," in Interdisciplinary Approach to Liquid Lubricant Technology, NASA SP-318, ed. by P.M. Ku, pp. 527-568, (1973).

29. Shogrin, B., Jones, W.R., Jr., Herrera-Fierro, P., Lin, T-Y and Kawa, H.: "Evaluation of BoundaryEnhancement Additives for Perfluoropolyethers," NASA TM-107393, Lewis Research Center, Cleveland, $\mathrm{OH}(1996)$.

30. Mori, S., Itoh, M., and Moriuchi, T.: "Relationship between the Tribological Properties of Perfluoroalkyl Polyether Oils and their Molecular Structure (Part 1): Lubricating Properties," Japanese J. of Trib., 40, 11, pp. 1-12, (1995).

31. Masuko, M., Fujinami, I., and Okabe, H.: "Lubrication Performance of Perfluoropolyalkylethers under High Vacuum," Wear, 159, pp. 249-256, (1992).

32. Pepper, S. and Kingsbury, E.P.: "Destruction of Fomblin Z-25 by Different Bearing Metals," Proceedings, Int. Rolling Element Bearing Symp., Orlando, FL, April 28-30, (1997).

33. Lauer, J.L. and Jones, W.R.: "Friction Polymers," ASLE Special Publication SP-21, Tribology and Mechanics of Magnetic Storage Systems, Vol. III, pp. 14-23, October, (1986). 
TABLE I.--PRIMARY CHEMICAL STRUCTURES OF SPACE LUBRICANTS TESTED

\begin{tabular}{|c|c|}
\hline Name & Structure \\
\hline PFPE S-200 & $\mathrm{C}_{3} \mathrm{~F}_{7} \mathrm{O}\left(\mathrm{CF}_{2} \mathrm{CF}_{2} \mathrm{CF}_{2} \mathrm{O}\right)_{x} \mathrm{C}_{2} \mathrm{~F}_{3}$ \\
\hline PFPE $14.3 \mathrm{AC}$ & $\mathrm{C}_{3} \mathrm{~F}_{7} \mathrm{O}\left[\mathrm{CF}\left(\mathrm{CF}_{3}\right) \mathrm{CF}_{2} \mathrm{O}\right]_{2} \mathrm{C}_{2} \mathrm{~F}_{5}$ \\
\hline PFPE $7-25$ & $\mathrm{CF}_{3} \mathrm{O}\left(\mathrm{CF}_{2} \mathrm{CF}_{2} \mathrm{O}\right)_{x}\left(\mathrm{CF}_{2} \mathrm{O}\right)_{3} \mathrm{CF}_{3}$ \\
\hline MAC 2001a & Mixlure of di- and tri(2-octyldodecyl)-Lyclopentane \\
\hline MAC 2001 (Formulated) & $\begin{array}{l}\text { Mixture of di- and tri(2-octyldodecyl)-cyclopentane + a Mixture } \\
\text { of Phosphate Esters (an antiwear additive) and a Hindered Phenol } \\
\text { (an antioxidant) }\end{array}$ \\
\hline PAO- 100 & Mixture of Branched Hydrocarbons \\
\hline Pentasilaydrocarbon SiHC & $\mathrm{Si}\left[\mathrm{C}_{3} \mathrm{H}_{6} \mathrm{Si}\left(\mathrm{C}_{\mathrm{i} 2} \mathrm{H}_{2.5}\right)_{3} \mathrm{~L}_{4}\right.$ \\
\hline
\end{tabular}

TABLE II-PHYSICAL PROPERTIES OF TEST LUBRICANTS (Manufacturer's Data)

\begin{tabular}{|c|c|c|c|c|c|}
\hline Lubricant & $\begin{array}{c}\text { Average } \\
\text { molecular } \\
\text { weight }\end{array}$ & $\begin{array}{l}\text { Viscosity al } \\
20^{\circ} \mathrm{C} \text {, cS }\end{array}$ & $\begin{array}{l}\text { Viscosity } \\
\text { index }\end{array}$ & $\begin{array}{l}\text { Pour pont, } \\
{ }^{\circ} \mathrm{C}\end{array}$ & $\begin{array}{l}\text { Vapor pressure, } \\
\text { (torr) at } 20^{\circ} \mathrm{C}\end{array}$ \\
\hline PFPE Z-25 & 9500 & 255 & 355 & -66 & $2.9 \times 10^{-\mathrm{F}}$ \\
\hline PFPE $143 \mathrm{AC}$ & 6250 & 800 & 134 & -35 & $2 \times 10^{-8}$ \\
\hline PFPE S-200 & 8400 & 500 & 210 & -53 & $1 \times 10^{-17}$ \\
\hline MAC 200Ia & 868 & ${ }^{7} 107$ & 1.37 & -57 & ${ }^{n} 3 \times 10^{-11}$ \\
\hline$\overline{M A C} 2001$ & 868 & ${ }^{3} 107$ & 137 & -5.5 & ${ }^{\mathrm{h}} 1 \times 10^{-8}$ \\
\hline PAO-100 & 2000 & 1400 & 168 & -20 & $\mathrm{NM}$ \\
\hline SiHC & 2336 & 143 & 169 & $\mathrm{NM}$ & $\mathrm{NM}$ \\
\hline
\end{tabular}

${ }^{\text {AAt }} 40^{\circ} \mathrm{C}$

${ }^{\mathrm{H}} \mathrm{At} 25^{\circ} \mathrm{C}$

NM-Not measured

TABLE III --WEAR RATES AND FRICTION COEFFICIENTS OF THE TEST LUBRICANTS

\begin{tabular}{|l|c|c|c|}
\hline \multicolumn{1}{|c|}{ Lubricant, number runs } & $\begin{array}{c}\text { Mean wear rate, } \\
\times 10^{-9} \mathrm{~mm}^{3} / \mathrm{mm}\end{array}$ & $\begin{array}{c}\text { Wear rate standard } \\
\text { deviation, } \\
\times 10^{-9} \mathrm{~mm}^{3 / / m m}\end{array}$ & $\begin{array}{c}\text { Mean and range of } \\
\text { friction coefficient }\end{array}$ \\
\hline PFPE 143 AC (6) & 0.21 & 0.030 & $0.12(0.08-0.20)$ \\
\hline PFPE S-200 (6) & 0.70 & 0.31 & $0.11(0.09-0.13)$ \\
\hline PFPE Z-25 (4) & 1.7 & 0.16 & $0.08(0.05-0.10)$ \\
\hline MAC 2001a (4) & 0.058 & 0.007 & $0.11(0.08-0.15)$ \\
\hline MAC 200I (Formulated) (5) & 0.037 & 0.014 & $0.09(0.08-0.13)$ \\
\hline Silahydrocarbon SiHC (4) & 0.033 & 0.007 & $0.08(0.07-0.09)$ \\
\hline Polyalphaolefin PAO-100 (5) & 0.13 & 0.11 & $0.10(0.09-0.14)$ \\
\hline
\end{tabular}




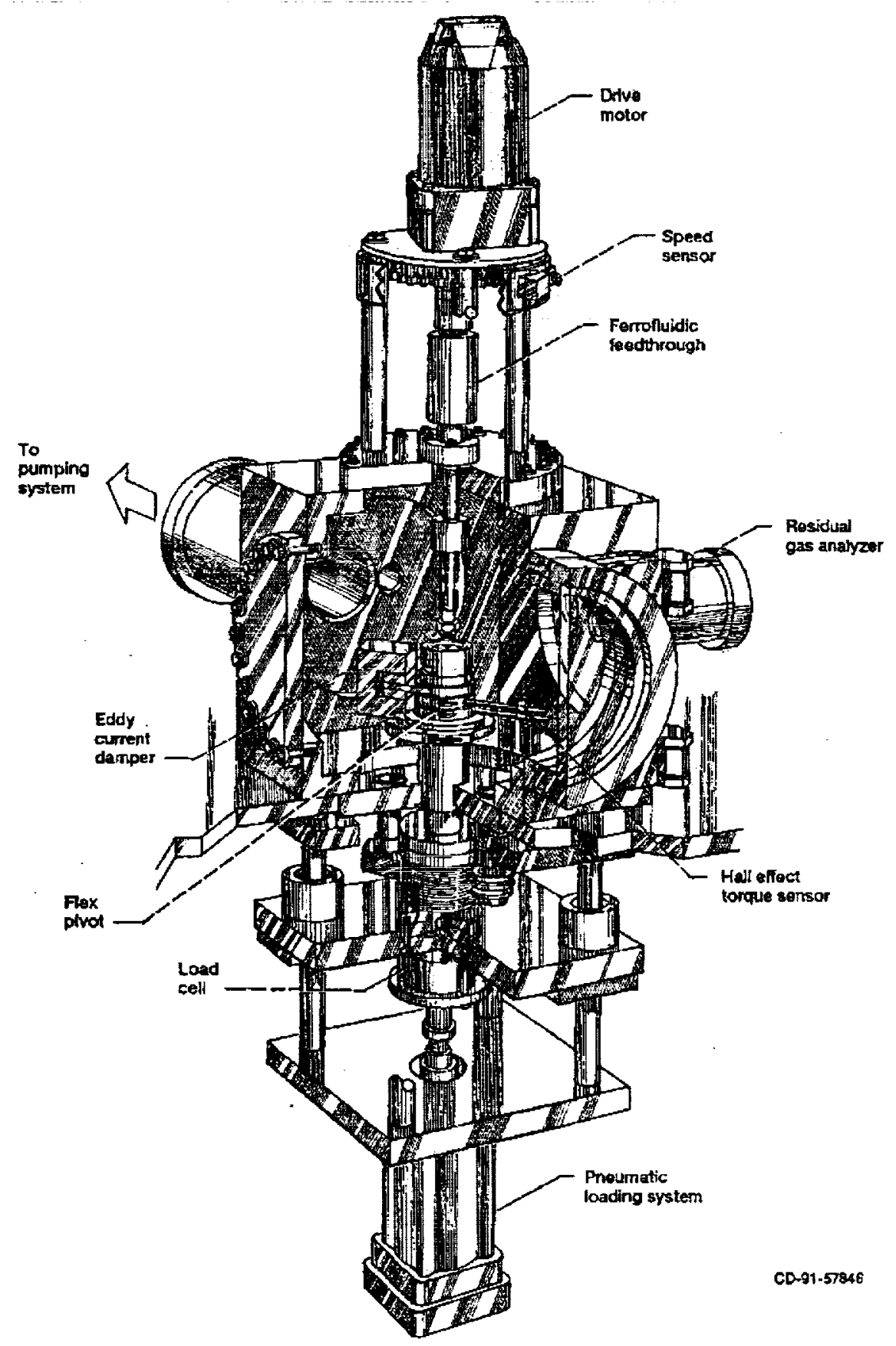

Figure 1.-Vacuum tribometer. 


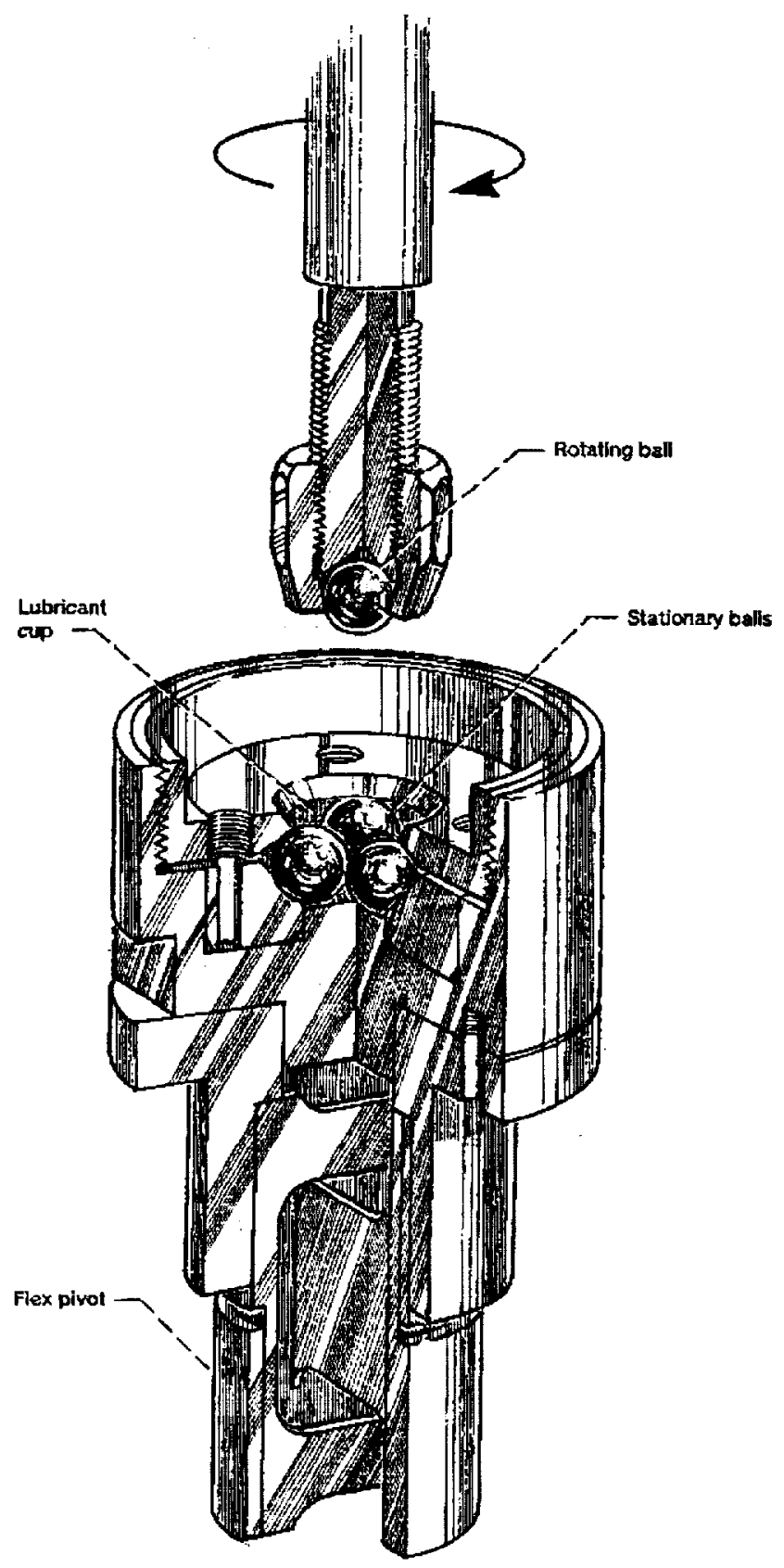

Figure 2.-Specimen Configuration. 
Four-Ball Apparatus

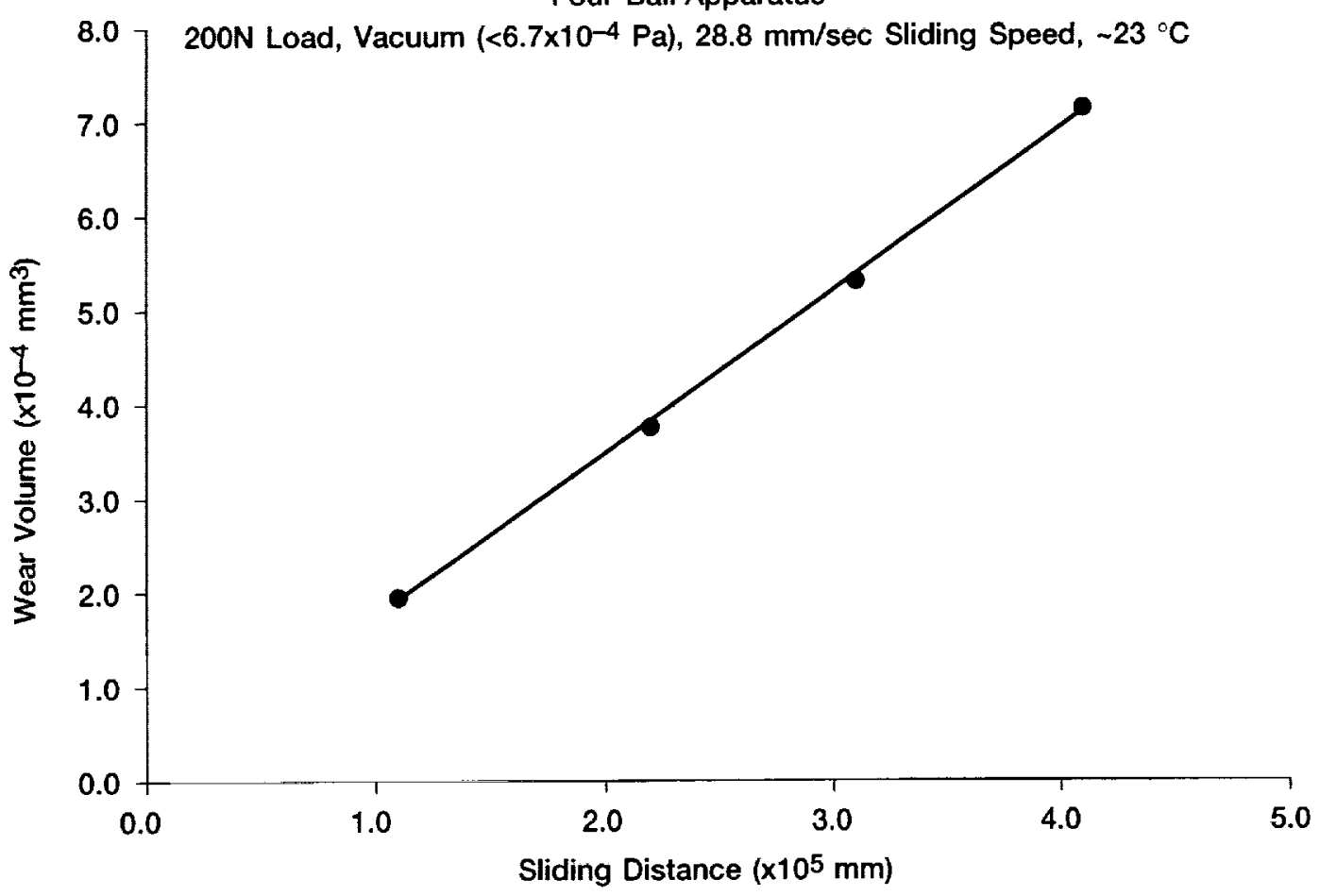

Figure 3.-Wear volume as a function of sliding distance for PFPE Z-25.

Four-Ball Apparatus

$200 \mathrm{~N}$ Load, Vacuum $\left(<6.7 \times 10^{-4} \mathrm{~Pa}\right), 28.8 \mathrm{~mm} / \mathrm{sec}$ Sliding Speed, $\sim 23^{\circ} \mathrm{C}$

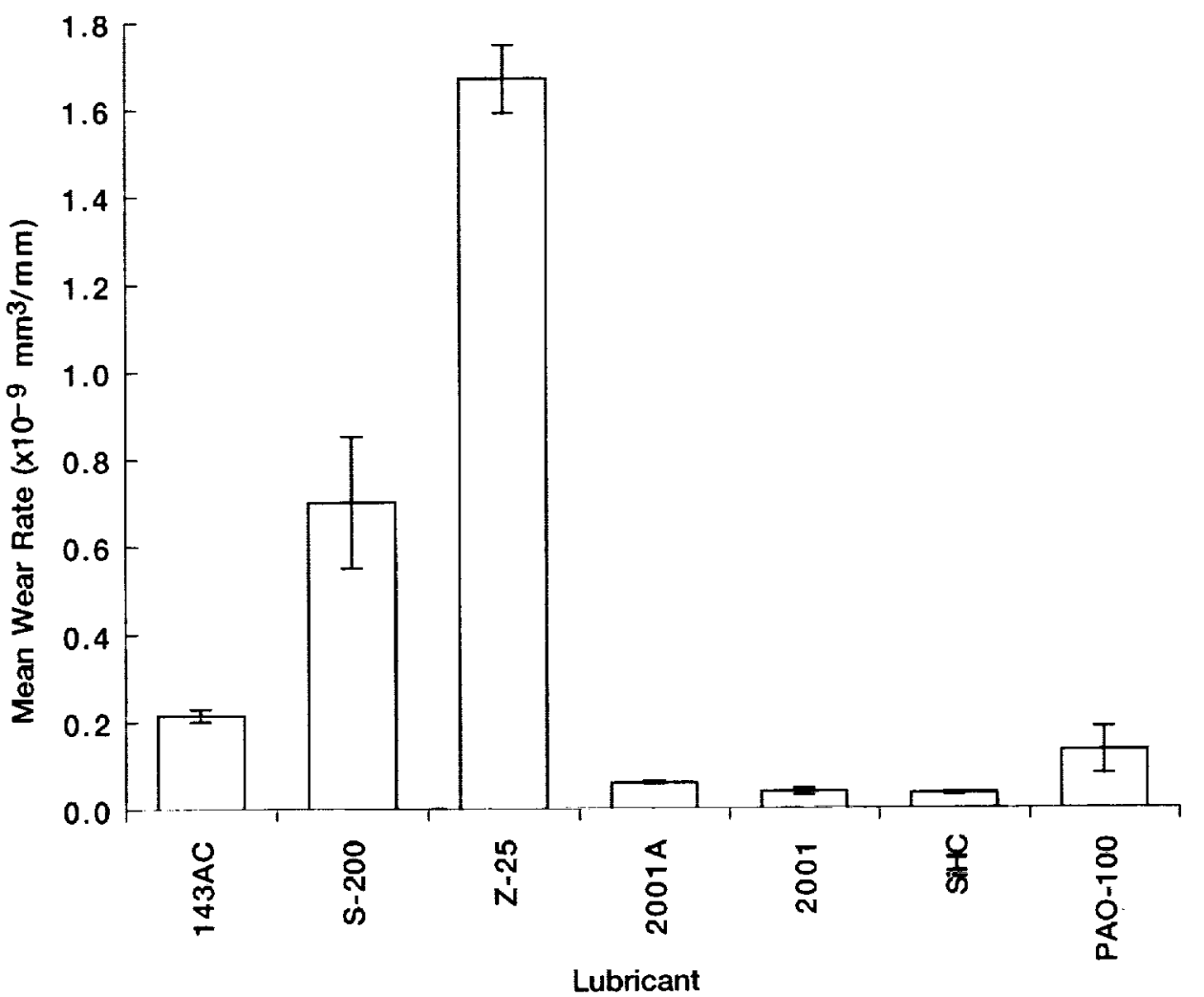

Figure 4.-Mean wear rates of the lubricants tested. Error bars represent one standard deviation. 
Four-Ball Apparatus

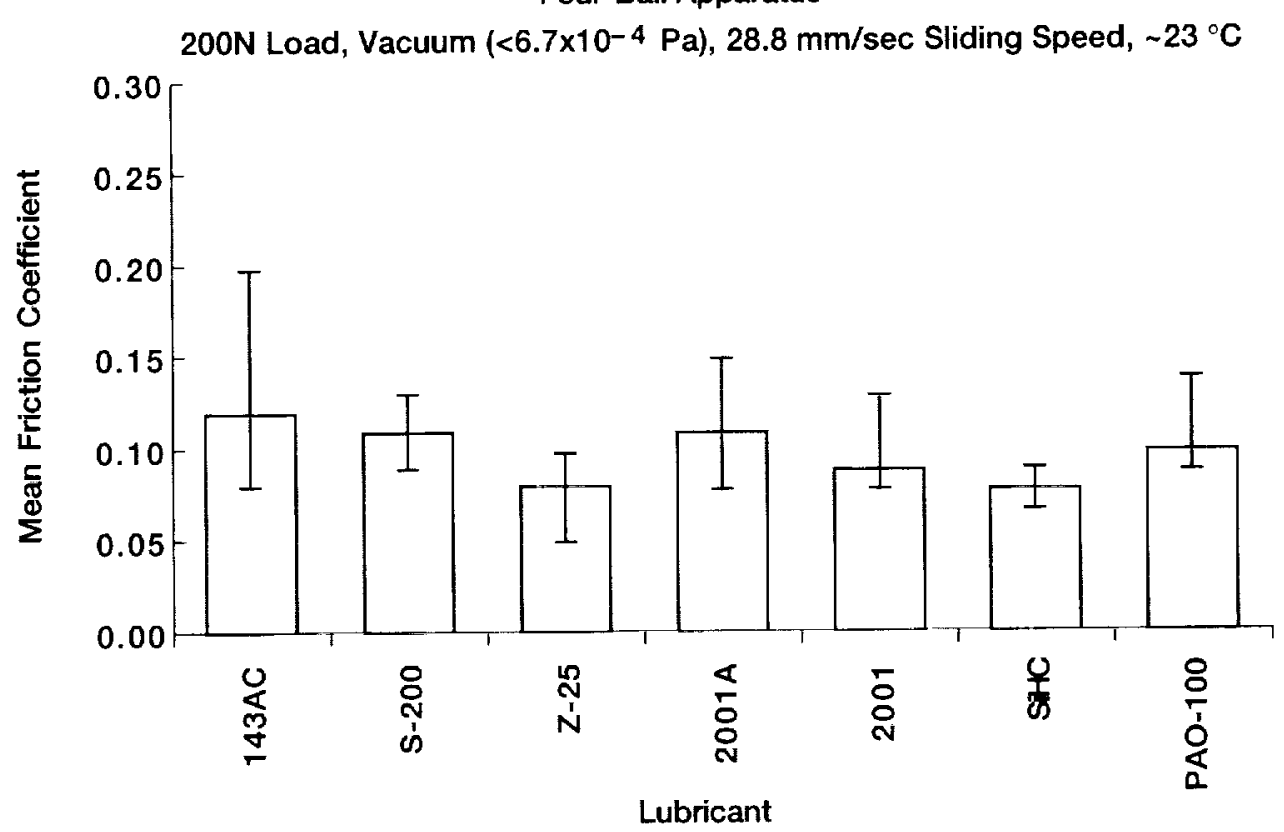

Figure 5.-Mean friction coefficients of the lubricants tested. Error bars represent one standard deviation.

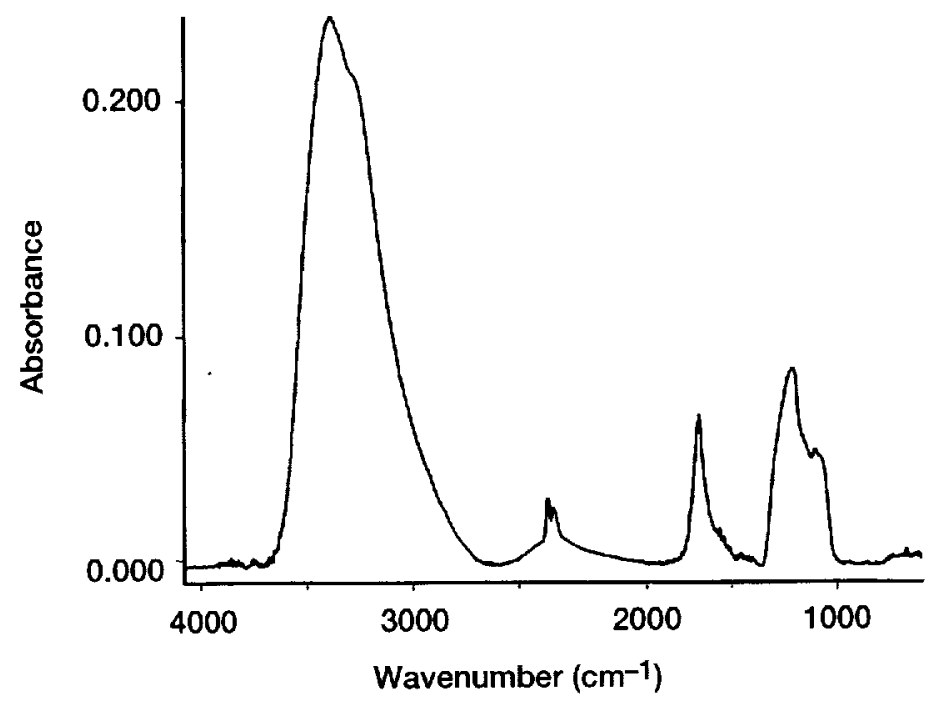

Figure 6.--Infrared spectrum of wear debris off wear scar for PFPE Z-25 lubricant. 


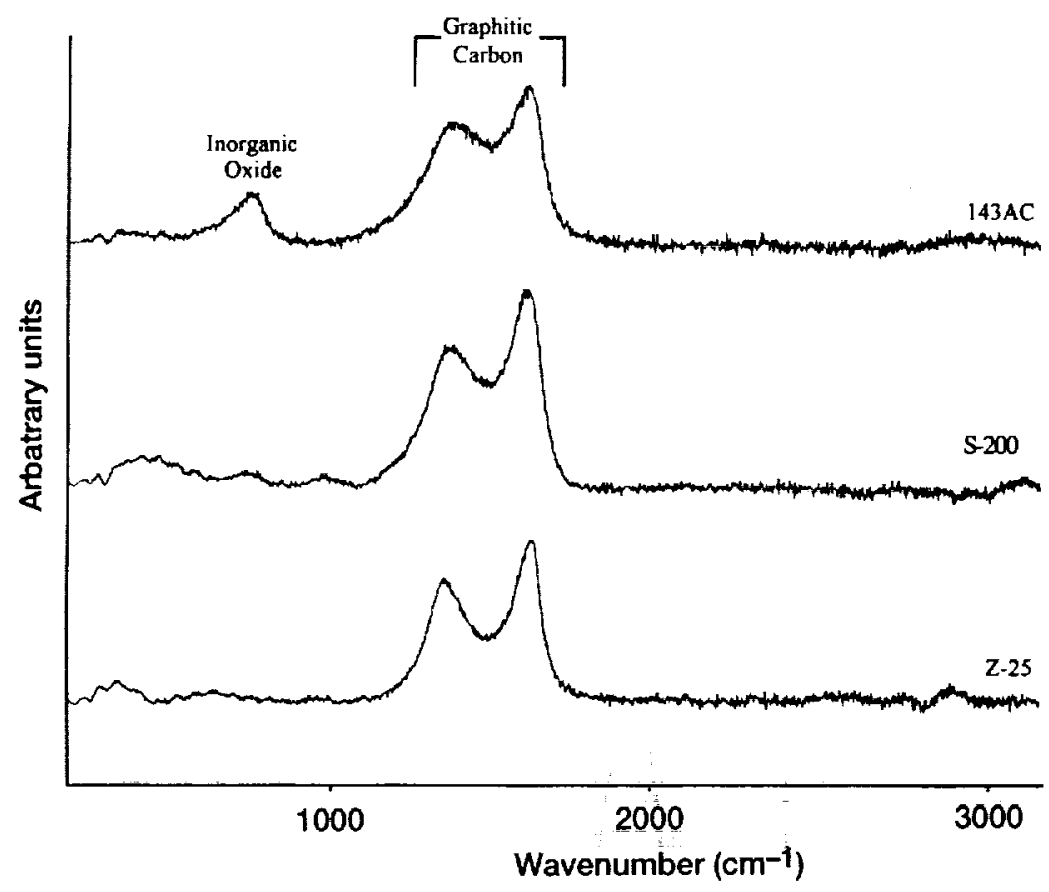

Figure 7.-Raman spectra of wear debris off wear scar for three PFPE lubricants $(Z-25,143 A C, S-200)$. 


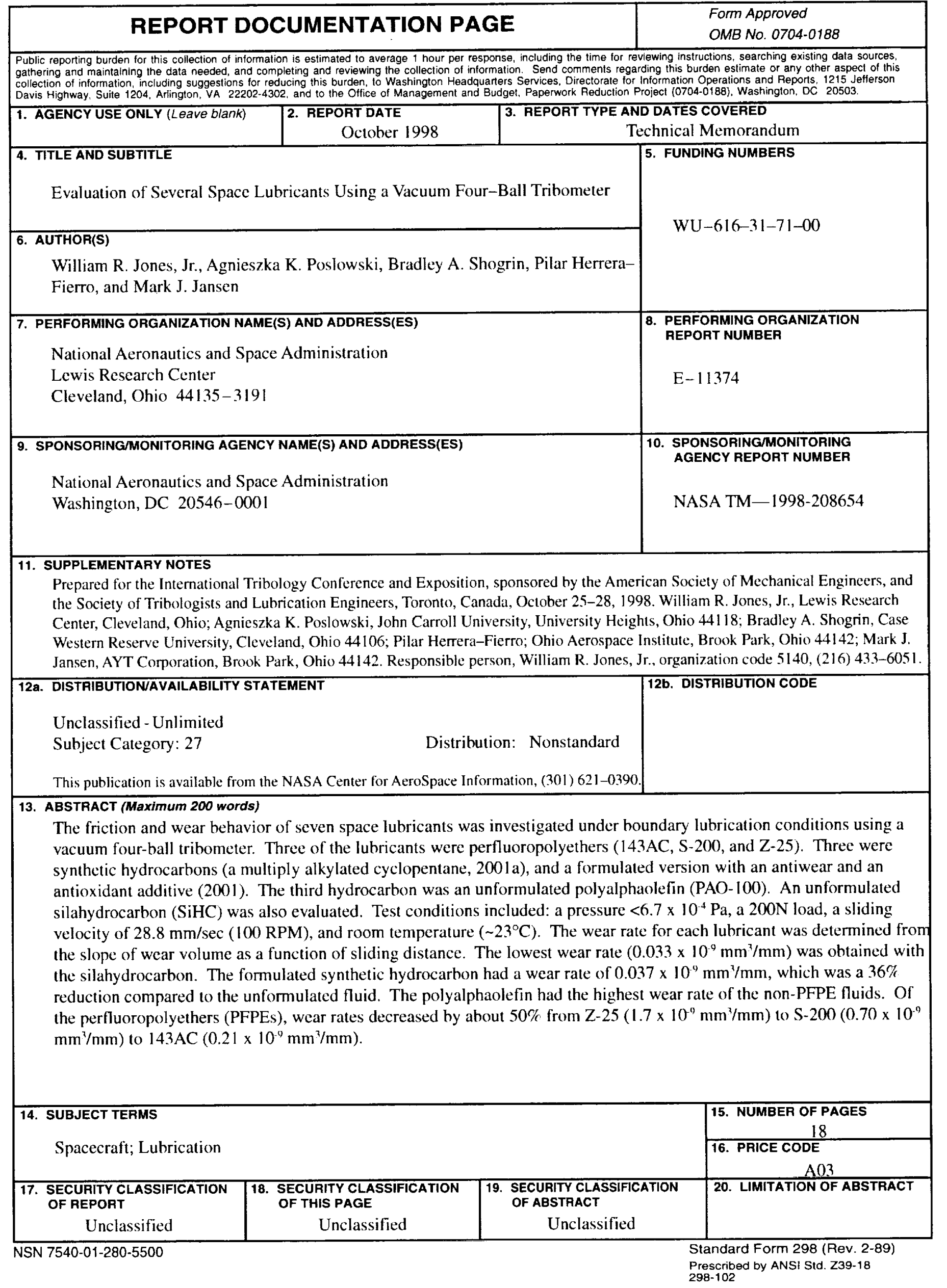


$7 \mathrm{I}$ 